\title{
FGFR2 Promotes Gastric Cancer Progression by Inhibiting the Expression of Thrombospondin4 via PI3K-Akt-Mtor Pathway
}

\author{
Tingting Huang ${ }^{a}$ Dian Liu ${ }^{\mathrm{a}}$ Yihua Wanga,b Piao Lia ${ }^{\mathrm{a}} \quad$ Li Sun $^{\mathrm{a}}$ \\ Huihua Xionga Yuhong Dai ${ }^{a} \quad$ Man Zou $^{a}$ Xianglin Yuan ${ }^{a}$ Hong Qiu ${ }^{a}$ \\ aDepartment of Oncology, Tongji Hospital, Tongji Medical College, Huazhong University of Science \\ and Technology, Wuhan, China, 'biological Sciences, Faculty of Natural \& Environmental Sciences, \\ University of Southampton, Southampton, United Kingdom
}

\author{
Key Words \\ Gastric cancer • FGFR2 • Thrombospondin4 • MTOR
}

\begin{abstract}
Background/Aims: Fibroblast growth factor receptor 2 (FGFR2) has attracted considerable interest as a therapeutic target in gastric cancer (GC). There is growing evidence to suggest that the bioavailability of the potent pro-tumor function of FGFR2 is associated with thrombospondins (TSPs). As a follow-on from our previous study, here we evaluated the potential clinical significance and mechanism of the relationship between FGFR2 and TSP4 in GC. Methods: Expression levels of FGFR2 and TSP4 were detected by immunohistochemistry in GC tissue microarray slides. SGC7901 and MKN28 cell lines were used to confirm the relationship between FGFR2 and TSP4. In vitro cell viability, colony formation, and invasion and migration assays were performed to evaluate the effect of FGFR2-TSP4 axis on tumor cell activities. The mechanism of TSP4 regulated by FGFG2 was explored via small molecular inhibitors in vitro and a xenograft model. Results: FGFR2 was shown to be markedly overexpressed in GC tissues and was correlated with a high risk of lymph node metastasis, late clinical stage, and poor prognosis. Low TSP4 expression was associated with shorter overall survival (OS) and advanced stage in GC patients. Interestingly, correlation analysis indicated that FGFR2 was negatively associated with TSP4. Indeed, in vitro and in vivo experiments suggested FGFR2 activation could downregulate TSP4 expression, which played an important role in the proliferation, invasion and migration of GC cells. We also found involvement of the PI3K-AKT-mTOR pathway in the FGFR2-TSP4 axis. Conclusion: The FGFR2 signal promotes human GC progression through the downregulation of TSP4 via PI3K-AKT-mTOR pathway. Our findings provide a foundation for further investigating promising therapeutic strategies for GC overexpressing FGFR2.

(C) 2018 The Author(s)

Published by S. Karger AG, Basel




\section{Introduction}

Gastric cancer (GC) is a highly malignant tumor and is one of the major causes of cancerrelated deaths worldwide [1]. Despite therapeutic advances in recent decades, the clinical outcome of GC remains disappointing because the majority of GC patients have advancedstage disease at diagnosis and chemotherapy currently offers only a limited survival advantage [2]. Consequently, there is an urgent need to identify novel drug targets for GC and, to date, the development of novel therapeutic strategies has accompanied an improved understanding of the molecular underpinnings of GC [2].

Fibroblast growth factor receptors (FGFR1, FGFR2, FGFR3 and FGFR4) are an interesting family of transmembrane tyrosine kinase receptors and their role in tumorigenesis has been revealed in various cancers [3]. Fibroblast growth factors (FGFs) released from the extracellular matrix bind to FGFRs, which subsequently activate the intracellular kinase domain, resulting in the activation of downstream signaling such as the RAS-MAPK and/or PI3K/Akt pathways $[4,5]$. The FGF-FGFR pathway plays crucial roles in various physiological processes including cell proliferation, cell differentiation, and wound healing, as well as survival and angiogenesis $[3,6]$. The dysregulation of the FGFR signaling may be due to gene mutation, gene amplification, protein overexpression, or aberrant transcriptional regulation. Accordingly, FGFR2 has attracted considerable interest as a therapeutic target [7]. FGFR2 overexpression is observed in about $30 \%$ of GC patients, it is associated with scirrhous GC, diffuse type GC, depth of invasion, and type of cancer infiltration, and has a poorer prognosis than FGFR2 negative GC [8]. The identification of potential mechanisms of FGFR2 signaling should ultimately help to identify promising strategies to treat GC with overexpression of FGFR2.

Growing evidence suggests that the bioavailability of the potent pro-tumor function of FGFR2 is associatedwith thrombospondins (TSPs), which are a family of extracellular glycoproteins that mediate interactions between cells and the interactions of cells with underlying matrix components in the tumor microenvironment [9]. The TSP family consists of five members (TSP1-5) divided into two subgroups, TSP1/2 and TSP3/4/5, according to their functional domains. TSP4 plays critical roles in the heart, blood vessels, nervous system $[10,11]$, and was recently identified as a regulator of multiple cancers including prostate cancer, breast cancer and GC [12-14]. Specifically, the expression of TSP genes and proteins is altered in cancer cells after FGF administration $[15,16]$. However, the specific cellular and molecular mechanisms of TSP 4 are still unclear.

In this study, FGFR2 and TSP4 expression levels were analyzed in GC tissues and compared with normal gastric tissue samples, and their potential biological functions in vitro were investigated. We sought to clarify how TSP4, the downstream targetgene, is regulated by FGFR2 to facilitate the increased activity of GC cells.

\section{Materials and Methods}

\section{GC tissue microarray and immunohistochemistry}

Commercially available tissue microarray (TMA) slides (HStm-Ade180Sur-06, Shanghai Outdo Biotech Co., Ltd., Shanghai, China) with 90 matched pairs of primary GC samples and adjacent gastric tissues were purchased for immunohistochemistry (IHC) analysis. None of the patients had received any treatment prior to surgery. All procedures were approved by the Ethical Committee of Tongji Hospital. Specific primary antibodies against FGFR2 (1:100, TA503137, OriGene, USA) and TSP4 (1:100, AP19723b, Abgent, San Diego,CA) were used for IHC with a two-step protocol. The IHC score, which ranges from 0 to 9 , was calculated as the multiplication of staining intensity ( 0 for negative staining, 1 for weak staining, 2 for moderate staining and 3 for strong staining) and the percentage of positive cells $(0,<10 \%$ positive cells; 1 , $10-30 \%$ positive cells; $2,30-50 \%$ positive cells; and 3, $>50 \%$ positive cells). A final score $<4$ indicates low expression and that score $\geq 4$ indicates high expression. Each sample was evaluated by two pathologists and any lack of concurrence was evaluated by a third senior pathologist. 


\section{Cellular Physiology Cell Physiol Biochem 2018;50:1332-1345

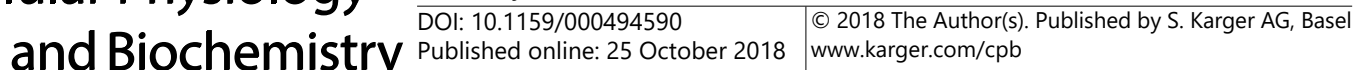

Huang et al.: FGFR2-TSP4 Axis in Gastric Cancer

\section{Cell culture and reagents}

Human GC cell lines, including SGC7901 and MKN28, were cultured in RPMI-1640 medium (Hyclone, USA) supplemented with $10 \%$ fetal bovine serum (FBS) (Gibco, USA). Cells were maintained in an atmosphere of $5 \% \mathrm{CO}_{2}$ in a humidified $37^{\circ} \mathrm{C}$ incubator. Recombinant FGF7 was purchased from Peprotech (AF-100-19, USA). LY294002, U0126, SP600125, SB203580, and RAD001 were from Promoter Biotechnology (Wuhan, China).

\section{Western blot analysis}

Western blot was performed as previously described [16]. Briefly, whole-cell lysates were collected, and protein concentrations were quantified by a BCA Protein Assay Kit (AR0146, Boster Biological Technology Ltd, Wuhan, China). The immunoblots were probed with primary antibodies overnight at $4{ }^{\circ} \mathrm{Cfollowed}$ by secondary antibodies at room temperature for $1 \mathrm{~h}$. The following primary antibodies were used according to the manufacturer's instructions: anti-phospho-FGFR2 (1:1000, 3471, Cell Signaling Technology, USA), antiFGFR2 (1:1000, TA503137, OriGene, USA), anti-TSP4 (AP19723b, Abgent, USA), anti-phospho-Akt (1:1000, 4060, Cell Signaling Technology, USA), anti-Akt (1:1000, 4691, Cell Signaling Technology, USA), anti-phosphomTOR (1:1000, 5536, Cell Signaling Technology, USA), anti-mTOR (1:1000, 20657-1-AP, Proteintech, USA), anti-phospho-p70S6K (1:1000, 9234, Cell Signaling Technology, USA), anti-p70S6K (1:1000, 14485-1AP, Proteintech, USA), anti-phospho-4EBP1 (1:1000, 2855, Cell Signaling Technology, USA), anti-4EBP1 (1:1000, 60246-1-lg, Proteintech, USA), and anti-GAPDH (1:5000, 60004-1-lg, Proteintech, USA). The blots were visualized using an enhanced chemiluminescencedetection kit (Thermo Fisher Scientific, USA).

\section{Lentivirus infection}

Stable knockdown of FGFR2 was carried out using pGV112-FGFR2-shRNA lentiviral expression plasmid (GeneChem, Shanghai, China) according to the manufacturer's instructions. Cells transfected with the vector were used as a negative control. After transfection, cells were transferred into medium containing $1 \mu \mathrm{g} / \mathrm{mL}$ puromycin for 1 week. The expression of FGFR2 was evaluated by western blot.

\section{Transient transfection}

The plasmids, including the negative control plasmid (vector), were designed and produced by GeneChem Co. The TSP 4 shRNA plasmid was designed to target the sequence 5'-TGAGGACTTCCAAGAGTTT-3'. The target sequence for knockdown of mTOR gene was 5'-CAGAATCTATTCATTCTTT-3'. To determine the direct effects of plasmids, cells were transfected with plasmids using Lipofectamine 2000 (Invitrogen, USA) in Opti-MEM medium (Gibco, USA). At $6 \mathrm{~h}$ after transfection, the medium was replaced with normal RPMI1640 medium containing $10 \%$ FBS and cells were incubated for $24 \mathrm{~h}$. Cells were cultured for another $24 \mathrm{~h}$ in RPMI-1640 medium containing FGF7. At $24 \mathrm{~h}$ after FGF7 stimulation, the total protein was extracted from the cells for an analysis of TSP4, mTOR, and p-mTOR expression.

\section{Cell viability assay}

Cell viability was detected by Cell Counting Kit-8 (CCK-8) assay. Cells were seeded in a 96-wellculture plate at a density of $1 \times 10^{5} \mathrm{cells} /$ well and precultured for $24 \mathrm{~h}$. Cells were treated with FGF7 for $48 \mathrm{~h}$ and 10 $\mu \mathrm{L}$ CCK-8 solution (AR1160, Boster Biological Technology, Wuhan, China) was added to each well for $1 \mathrm{~h}$. Absorbance at $450 \mathrm{~nm}$ was read by a microplate reader and all data were standardized to the control group.

\section{Colony formation assay}

Five-thousand cells were seeded into $6 \mathrm{~cm}$ plates and incubated for 21 days with FGF7. Cells were then fixed with methanol and dyed with crystal violet. Colonies were counted and photographed.

\section{In vitro invasion and migration assays}

Assays were performed using cell culture inserts (8- $\mu \mathrm{m}$ pore size) in a 24-well format (3422, Corning, USA). For the invasion assay, the insert membranes were precoated with diluted BD Matrigel ${ }^{\mathrm{TM}}$ Matrix (BD Biosciences, USA). Cells $\left(1 \times 10^{5}\right.$ cells/well $)$ in serum-free medium were transferred to the upper chamber. Medium containing 10\% FBS was added to the lower chamber as a chemoattractant. After incubation for 24 h, cells were fixed with methanol and stained with crystal violet. Non-invading cells were removed from the 


\section{Cellular Physiology Cell Physiol Biochem 2018;50:1332-1345

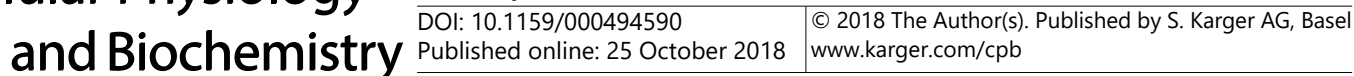 \\ Huang et al.: FGFR2-TSP4 Axis in Gastric Cancer}

upper chambers with cotton swabs. For the migration assay, cells were cultured under the same conditions without precoated Matrigel on the membranes. Finally, cells were photographed (200x) and counted in three randomly chosen fields.

\section{Xenograft model}

Animal experiments were carried out in accordance with the guidelines and approved protocols of the Ethics Committee of Tongji Hospital. Cells $\left(5 \times 10^{6}\right)$ were subcutaneously administered to the right upper back of each 5-week-old BALB/c nude mouse. Mice were then randomly grouped (n=6 per group) when tumors grew to about $5 \mathrm{~mm}$ in diameter. Mice were weighted twice a week. Tumor size was measured every 3 days via calipers, and tumor volume was calculated according to the formula: Tumor volume $=1 / 2\left(\mathrm{~L}^{2} \mathrm{~W}^{2}\right)$, $\mathrm{L}=$ Length and $\mathrm{W}=\mathrm{Width}$. After completion of the experiment, tumors were removed, measured, and fixed in formalin for IHC.

\section{Statistical analysis}

All experiments were performed at least three times. Numerical data are presented as means \pm standard error of mean (SEM). Individual group comparisons were performed using the Student's t-test. The relationships between FGFR2 or TSP4 expression and other clinicopathological parameters were analyzed using the Chi-square test or Fisher's exact test. Survival was compared between the groups using a log-rank test within a Kaplan-Meier type analysis. The association between FGFR2 and TSP4 was evaluated by correlation analysis, with a negative correlation at a correlation coefficiency of $r<0$. For univariate and multivariate analyses, the Cox proportional regression model was used. A p value of less than 0.05 in all cases was considered statistically significant.

\section{Results}

High expression of FGFR2 correlated with tumor progression and poor survival in GC patients

To examine the expression of FGFR2 in cancer and adjacent tissues in the stomach, IHC analysis was performed on a human TMA slide consisting of 90 matched pairs of primary GC samples and adjacent gastric tissues samples. The clinical characteristics of these 90 GC patients were shown in Table 1 . The median age of the patients at diagnosis was 63 years (range 28-88 years). In our experiments, FGFR2 was mainly expressed in the cytoplasm (Fig. 1A) and was overexpressed in 44 cases (48.9\%). As previously reported [16], FGFR2 was more strongly expressed in GC than in adjacent gastric tissue samples (Fig. 1B). In addition, high expression of FGFR2 was significantly associated with lymph node metastasis $(\mathrm{P}=0.002)$ and clinical stage $(\mathrm{P}=0.016$; Table 1). N0 and N1 tumors had much lower FGFR2 expression than N2 and N3 tumors. Patients with stage I or II GC expressed much less FGFR2 than those with stage III or IV GC. Survival analysis

Table 1. Correlation between FGFR2 or TSP4 expression and clinicopathological characteristics of GC patients. P value was generated by Chi-square test or Fisher's exact test. ${ }^{*} \mathrm{P}<0.05$ was considered as statistically significant

\begin{tabular}{|c|c|c|c|c|c|c|c|}
\hline \multirow[b]{2}{*}{ Parameter } & \multirow[b]{2}{*}{ No. } & \multicolumn{2}{|c|}{ FGFR2 expression } & \multicolumn{4}{|c|}{ TSP4 expression } \\
\hline & & Low & High & $P$ value & Low & High & $P$ value \\
\hline \multicolumn{8}{|l|}{ Age (years) } \\
\hline$<63$ & 44 & 19 & 25 & & 32 & 12 & \\
\hline$\geq 63$ & 46 & 27 & 19 & 0.141 & 30 & 16 & 0.442 \\
\hline \multicolumn{8}{|l|}{ Sex } \\
\hline Male & 53 & 28 & 25 & & 37 & 16 & \\
\hline Female & 37 & 18 & 19 & 0.696 & 25 & 12 & 0.821 \\
\hline \multicolumn{8}{|l|}{ Tumor size(cm) } \\
\hline$\leq 4$ & 32 & 18 & 14 & & 25 & 7 & \\
\hline$>4$ & 58 & 28 & 30 & 0.469 & 37 & 21 & 0.160 \\
\hline \multicolumn{8}{|l|}{ Differentiation } \\
\hline Poor & 50 & 23 & 27 & & 34 & 16 & \\
\hline Well+Moderate & 40 & 23 & 17 & 0.278 & 28 & 12 & 0.839 \\
\hline \multicolumn{8}{|l|}{ Tumor depth } \\
\hline $\mathrm{T} 1+\mathrm{T} 2+\mathrm{T} 3$ & 67 & 35 & 32 & & 46 & 21 & \\
\hline $\mathrm{T} 4$ & 23 & 11 & 12 & 0.715 & 16 & 7 & 0.935 \\
\hline \multicolumn{8}{|l|}{ Lymph node } \\
\hline $\mathrm{N} 0+\mathrm{N} 1$ & 35 & 25 & 10 & & 18 & 17 & \\
\hline $\mathrm{N} 2+\mathrm{N} 3$ & 55 & 21 & 34 & 0.002 & 44 & 11 & $\begin{array}{c}0.004 \\
*\end{array}$ \\
\hline \multicolumn{8}{|c|}{ Distant metastasis } \\
\hline м0 & 86 & 45 & 41 & & 58 & 28 & \\
\hline M1 & 4 & 1 & 3 & 0.285 & 4 & 0 & - \\
\hline \multicolumn{8}{|l|}{ Clinical stage } \\
\hline $\mathrm{I}+\mathrm{II}$ & 36 & 24 & 12 & & 20 & 16 & \\
\hline $\mathrm{III+IV}$ & 54 & 22 & 32 & $0.016^{*}$ & 42 & 12 & $0.026^{*}$ \\
\hline
\end{tabular}




\section{Cellular Physiology Cell Physiol Biochem 2018;50:1332-1345

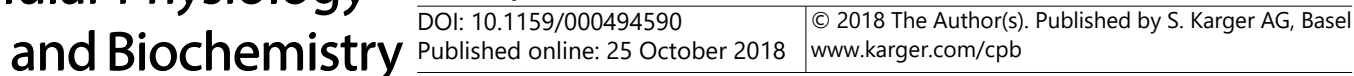

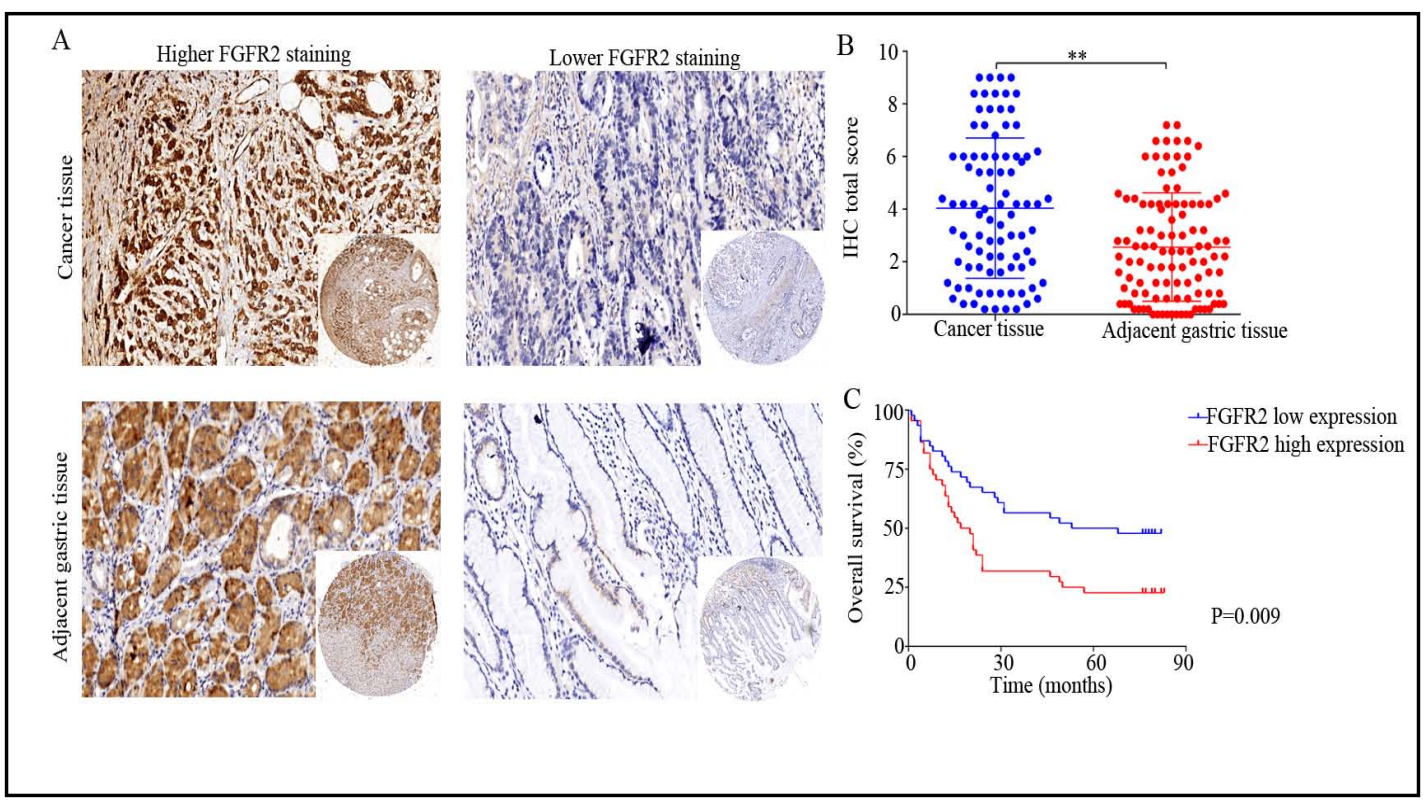

Fig. 1. Expression of FGFR2 in paired gastric cancer (GC) tumor and adjacent tissue samples, and survival analysis of GC patients. (A) Representative micrographs showing higher FGFR2 staining and lower FGFR2 staining in GC tissues and adjacent tissues (magnification, ×200). (B) Quantification of FGFR2 expression in GC tissues compared with adjacent tissues. (C) Kaplan-Meier survival curves of GC patients with FGFR2 high expression and FGFR2 low expression. Data are presented as mean \pm SEM $\left({ }^{* *} \mathrm{P}<0.01\right)$.

demonstrated that patients with FGFR2-low expression tumors had significantly longer overall survival (OS) than patients with FGFR2-high expression tumors ( $\mathrm{P}=0.009)$ (Fig. 1C). These results suggested that FGFR2 expression was increased in GC tissues and correlated with tumor progression. High expression of FGFR2 predicted a worse prognosis.

TSP4 expression was decreased in GC tissues, associated with OS, and negatively correlated with FGFR2 expression

In this present study, TSP4 expression was also identified by the TMA slides. TSP4 was expressed heterogeneously in the cytoplasm, and in the extracellular matrix in some cases (Fig. 2A). Lower expression level of TSP4 was observed in the GC tissues than in adjacent tissues (Fig. 2B). To determine parameters affecting TSP4-involved processes in GC, we further analyzed the correlation between TSP4 and other clinicopathological factors (Table 1). Patients with TSP4 low expression had a high risk of lymph node metastasis $(\mathrm{P}=0.004)$ and late clinical stage $(\mathrm{P}=0.026)$, indicating that low TSP4 expression may promote the progression of GC. As expected, low expression of TSP4 tended to predict a worse clinical outcome ( $\mathrm{P}=0.024)$ (Fig. 2C). We also investigated the association between FGFR2 and TSP4 expression by correlation analysis. As shown in Fig. 2D, the expression of TSP4 correlated negatively with FGFR2 expression, suggesting that the observed reduction in TSP4 expression was likely due to FGFR2 overexpression.

The results of the univariate and multivariate analysis were summarized in Tables 2 and 3. Univariate analysis demonstrated a significantly shorter OS in patients in seven categories: tumor size, tumor depth, lymph node metastasis, distant metastasis, clinical stage, and FGFR2 and TSP4 expression. In multivariate analysis, clinical stage tended to correlate with a poorer outcome $(\mathrm{P}=0.059)$, while other factors were not associated with OS. Thus, the expression levels of FGFR2 and TSP4 were not independent prognostic factors for GC. 


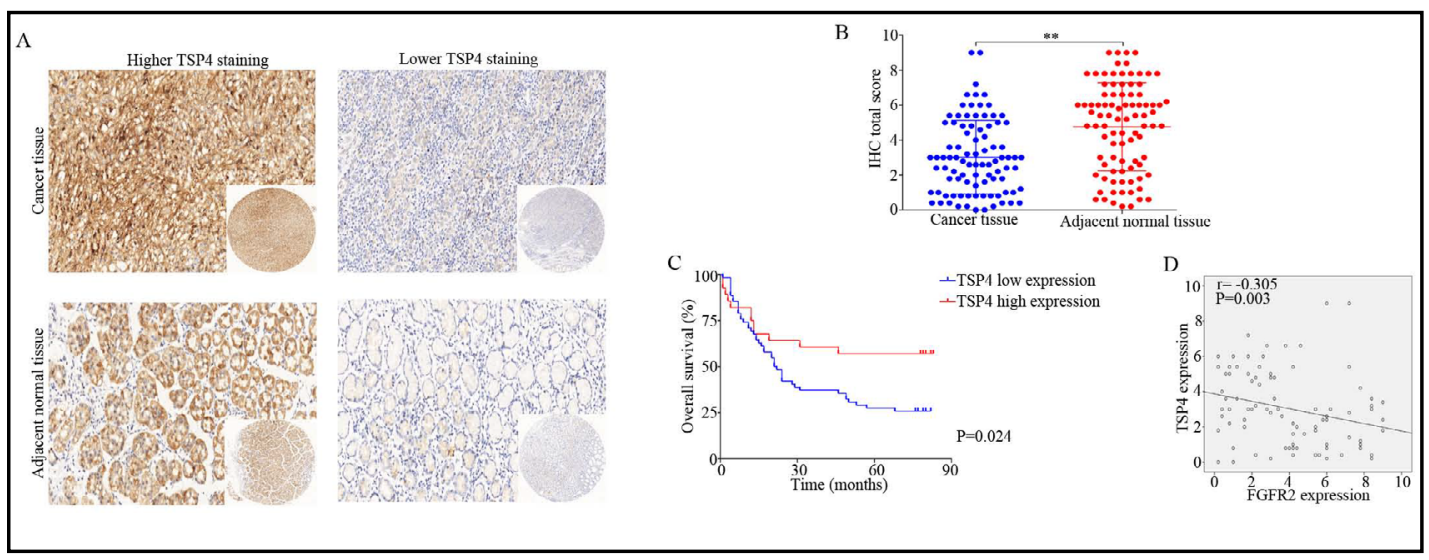

Fig. 2. Expression of TSP4 in paired GC tumor and adjacent tissue samples, correlation analysis between FGFR2 and TSP4 expression, and survival analysis of GC patients. (A) Representative micrographs showing higher TSP4 staining and lower TSP4 staining in GC tissues and adjacent tissues, respectively (magnification, $\times 200$ ). (B) Quantification of TSP4 expression in GC tissues compared with adjacent tissues. (C) KaplanMeier survival curves of GC patients with TSP4 high expression and TSP4 low expression. (D) Correlation analysis of FGFR2 and TSP4 expression. Data are presented as mean $\pm \operatorname{SEM}\left({ }^{* *} \mathrm{P}<0.01\right)$.

Table 2. Univariate Cox regression analyses for OS. CI: Confidence interval; HR: hazard ratio; ${ }^{*} \mathrm{P}<0.05,{ }^{* *} \mathrm{P}<0.01$

\begin{tabular}{lcccc}
\hline Variable & No. & HR & $95 \%$ CI & P value \\
\hline Age (years) & & & & \\
$<63$ & 44 & & & \\
$\geq 63$ & 46 & 1.616 & $0.958-2.726$ & 0.069 \\
Sex & & & & \\
Male & 53 & & & \\
Female & 37 & 0.682 & $0.407-1.144$ & 0.145 \\
Tumor size(cm) & & & & \\
$\leq 4$ & 32 & & & \\
$>4$ & 58 & 0.536 & $0.301-0.954$ & $0.031^{*}$ \\
Differentiation & & & & \\
Poor & 50 & & & \\
Well+Moderate & 40 & 1.674 & $0.977-2.869$ & 0.058 \\
Tumor depth & & & & \\
T1+T2+T3 & 67 & & & \\
T4 & 23 & 0.486 & $0.281-0.840$ & $0.008^{* *}$ \\
Lymph node & & & & \\
N0+N1 & 35 & & & \\
N2+N3 & 55 & 0.106 & $0.049-0.228$ & $<0.001^{* *}$ \\
Distant metastasis & & & & \\
M0 & 86 & & & \\
M1 & 4 & 0.252 & $0.088-0.722$ & $0.006^{* *}$ \\
Clinical stage & & & & \\
I+II & 36 & & & \\
III+IV & 54 & 0.113 & $0.054-0.236$ & $<0.001^{* *}$ \\
FGFR2 expression & & & & \\
Low & 46 & & & \\
High & 44 & 0.506 & $0.299-0.857$ & \\
TSP4 expression & & & & \\
Low & & & & \\
\hline & & & \\
High & & & \\
\hline
\end{tabular}

Table 3. Multivariate Cox regression analyses for OS. CI: Confidence interval; HR: hazard ratio

\begin{tabular}{|c|c|c|c|c|}
\hline Variable & No. & HR & $95 \% \mathrm{CI}$ & $P$ value \\
\hline \multicolumn{5}{|c|}{ Tumor size $(\mathrm{cm})$} \\
\hline$\leq 4$ & 32 & & & \\
\hline$>4$ & 58 & 0.601 & $0.321-1.125$ & 0.111 \\
\hline \multicolumn{5}{|c|}{ Tumor depth } \\
\hline $\mathrm{T} 1+\mathrm{T} 2+\mathrm{T} 3$ & 67 & & & \\
\hline $\mathrm{T} 4$ & 23 & 1.242 & $0.684-2.255$ & 0.477 \\
\hline \multicolumn{5}{|l|}{ Lymph node } \\
\hline $\mathrm{N} 0+\mathrm{N} 1$ & 35 & & & \\
\hline $\mathrm{N} 2+\mathrm{N} 3$ & 55 & 0.299 & $0.073-1.217$ & 0.092 \\
\hline \multicolumn{5}{|c|}{ Distant metastasis } \\
\hline M0 & 86 & & & \\
\hline M1 & 4 & 0.414 & $0.142-1.207$ & 0.106 \\
\hline \multicolumn{5}{|c|}{ Clinical stage } \\
\hline $\mathrm{I}+\mathrm{II}$ & 36 & & & \\
\hline III+IV & 54 & 0.286 & $0.078-1.046$ & 0.059 \\
\hline \multicolumn{5}{|c|}{ FGFR2 expression } \\
\hline Low & 46 & & & \\
\hline High & 44 & 0.865 & $0.437-1.582$ & 0.638 \\
\hline \multicolumn{5}{|c|}{ TSP4 expression } \\
\hline Low & 62 & & & \\
\hline High & 28 & 0.867 & $0.392-1.919$ & 0.725 \\
\hline
\end{tabular}




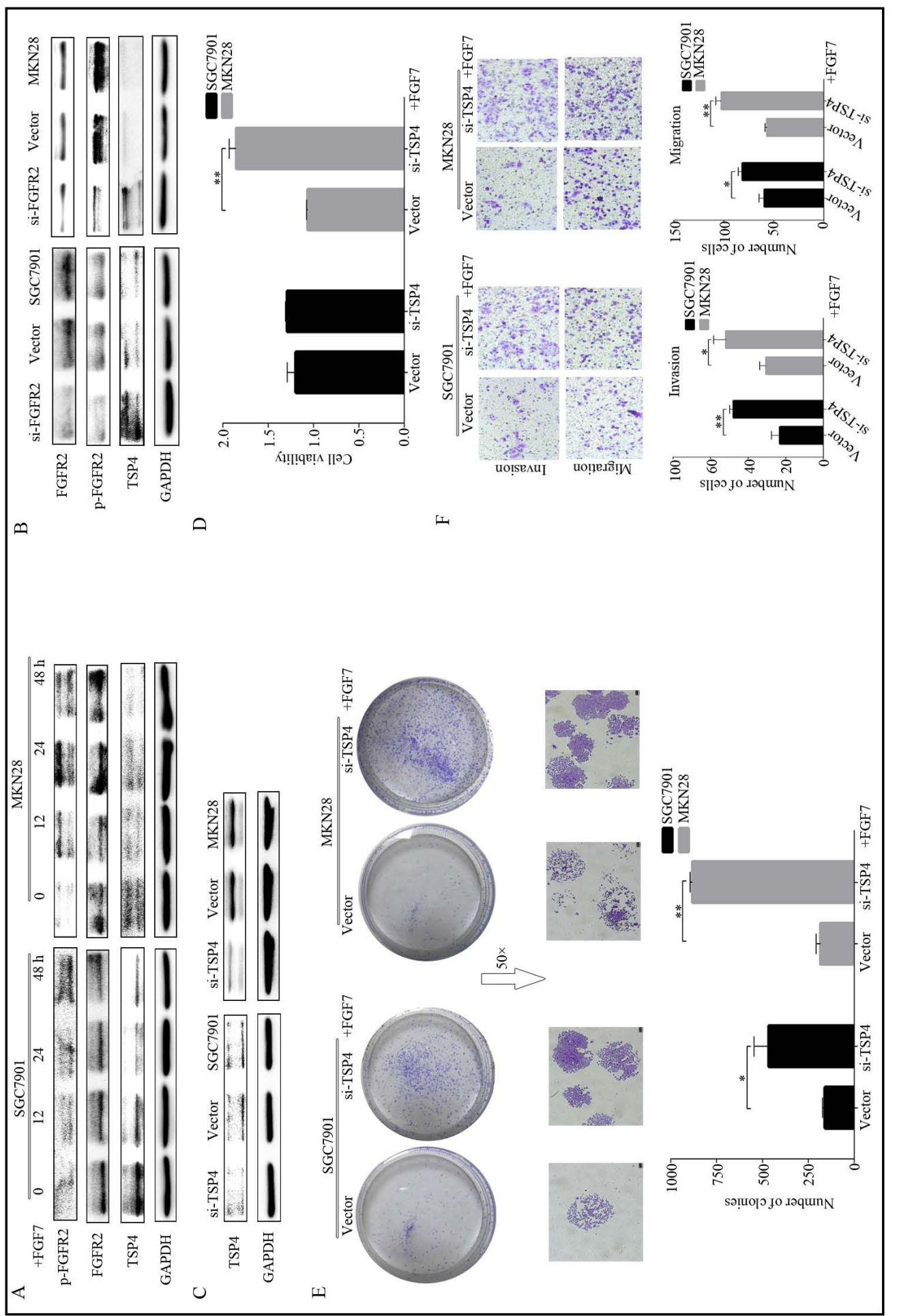

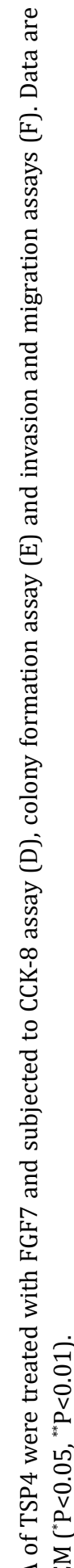

ชै

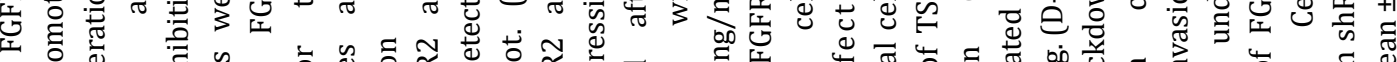

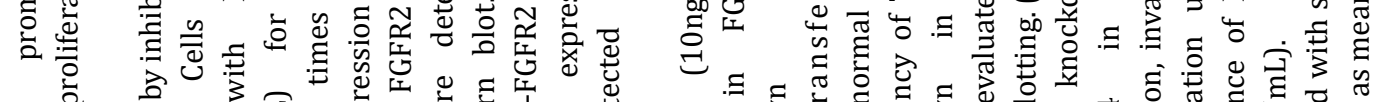

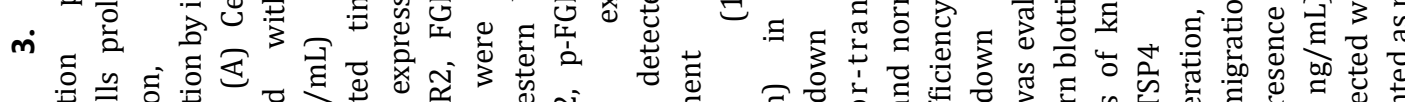

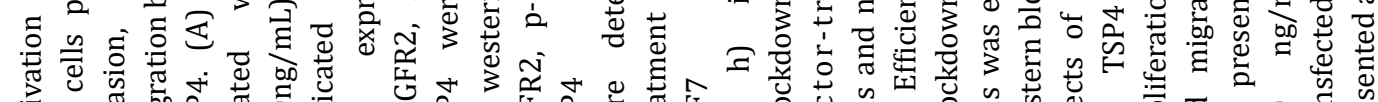

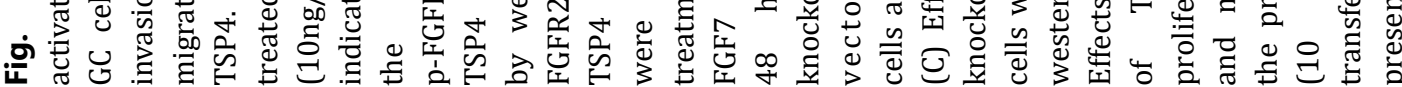
KARGER 


\section{Cellular Physiology Cell Physiol Biochem 2018;50:1332-1345 \begin{tabular}{ll|l} 
DOI: 10.1159/000494590 & $\begin{array}{l}\text { O } 2018 \text { The Author(s). Published by S. Karger AG, Basel } \\
\text { www.karger.com/cpb }\end{array}$ \\
\cline { 2 - 4 }
\end{tabular} \\ Huang et al.: FGFR2-TSP4 Axis in Gastric Cancer}

Activated FGFR2 signal promoted GC cells proliferation, invasion, and migration via downregulation of TSP4

Two GC cell lines (SGC7901 and MKN28) were treated with FGF7, which specifically binds and rapidly activates the FGFR2 signaling pathway. We determined the amount of p-FGFR2, FGFR2 and TSP4 by western blot at $0 \mathrm{~h}, 12 \mathrm{~h}, 24 \mathrm{~h}$, and $48 \mathrm{~h}$ after treatment. Fig. 3A revealed that FGFR2 tyrosine phosphorylation was significantly stimulated by the addition of FGF7 in both two cell lines. Interestingly, TSP4 was found to be inhibited in these cell lines, which was likely a result of FGFR2 activation. We also infected SGC7901 and MKN28 cells with FGFR2 shRNA using lentiviral vectors and achieved efficient FGFR2 knockdown. FGFR2 knockdown was accompanied by decreased p-FGFR2, whereas TSP4 was highly elevated in the FGFR2-knockdown cells (Fig. 3B). Thus, overexpressed and highly activated FGFR2 signaling is the key driver of the downregulation of TSP4.

To evaluate the biological effects of FGFR2-TSP4 axis, we performed transient transfection on SGC7901 and MKN28 cells to silence TSP4. A reduction in TSP4 protein expression was observed $48 \mathrm{~h}$ after transfection compared with vector-transfected cells (Fig. 3C). We then examined the effect of TSP4 knockdown in cell proliferation, invasion, and migration under the presence of FGF7 $(10 \mathrm{ng} / \mathrm{mL})$. Cell viability was determined by the CCK-8 assay. In TSP4knockdown cells, we observed an increase in cell viability compared with vector-transfected cells after FGF7 treatment. However, a significant change was found only in MKN28 cells (Fig. 3D). Knockdown of TSP4 expression significantly increased the effects of FGF7 on the proliferation, invasion, and migration of GC cells (Fig. 3E and 3F). These results suggested that FGFR2 promotes GC progression by inhibiting the expression of TSP4.

\section{FGFR2 inhibited TSP4 expression via PI3K-AKT-mTOR pathway}

To understand the molecular mechanisms of FGFR2-induced the inhibition of TSP4, a series of inhibitors, including LY294002 (PI3K inhibitor), U0126 (MEK inhibitor), SB203580 (p38 MAPK inhibitor), SP600125 (JNK inhibitor), and RAD001 (mTOR inhibitor), were applied to identify the related signaling pathway. As shown in Fig. 4A, TSP4 inhibition by FGFR2 was partially abrogated after treatment with LY294002 or RAD001 in both two cell lines.

We then investigated the effect of FGFR2 activation on the AKT-mTOR signaling pathway. Western blots showed that the administration of FGF7 to GC cells resulted in an increase in the phosphorylation of AKT, mTOR and p70S6K. In contrast, 4EBP1 phosphorylation was substantially decreased (Fig. 4B). Accordingly, the phosphorylation of AKT, mTOR and p70S6K was blocked and 4EBP1 became reactivated in FGFR2-knockdown cells (Fig. 4C). Moreover, mTOR phosphorylation was reduced after mTOR knockdown, and accompanied by increased TSP4 (Fig. 4D). These data suggested that FGFR2 served to regulate the expression of TSP4 via the PI3K-AKT-mTOR pathway.

mTOR played a crucial role in the FGFR2-TSP4 axis in vivo

Next, we examined whether mTOR was associated with FGFR2-TSP4 axis in vivo. Twentyone days after the subcutaneous injection of cancer cells into nude mice, mice treated with RAD001 had smaller subcutaneous tumors than those injected with vector cells. No significant change was observed among FGFR2-knockdown cells and vector cells (Fig. 5A). IHC staining of TSP4 demonstrated significantly increased expression in the vector+RAD001 group versus the vector group. Similarly, FGFR2 knockdown induced an increase of TSP4 expression (Fig. 5B). Taken together, these results showed that mTOR played a crucial role in the FGFR2-TSP4 axis. 


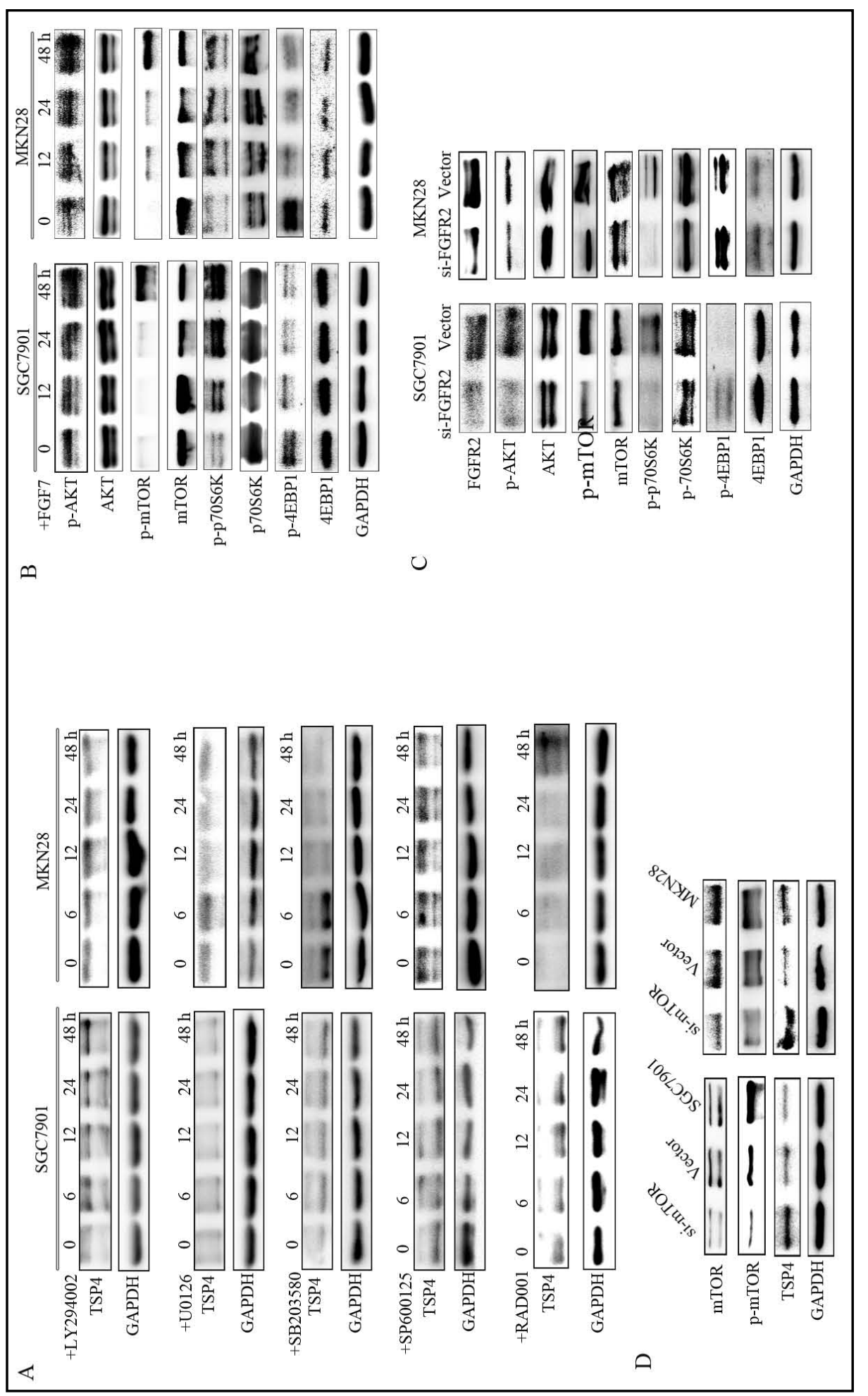

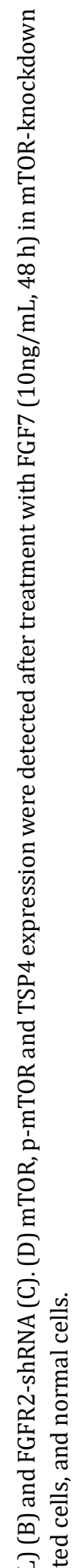

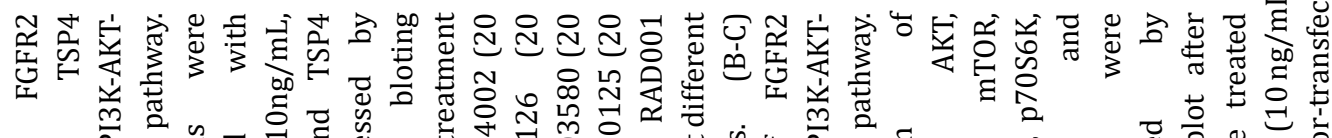

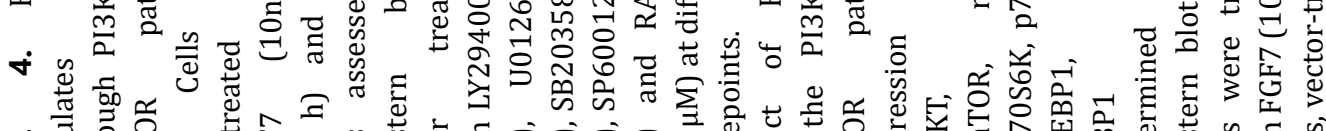

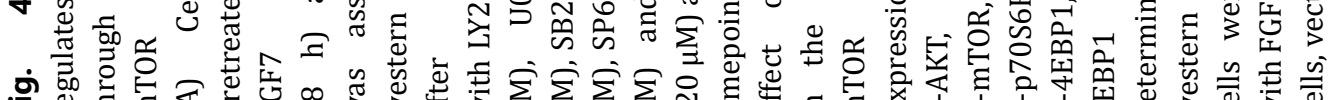

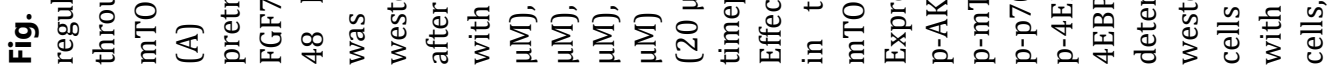
KARGER 


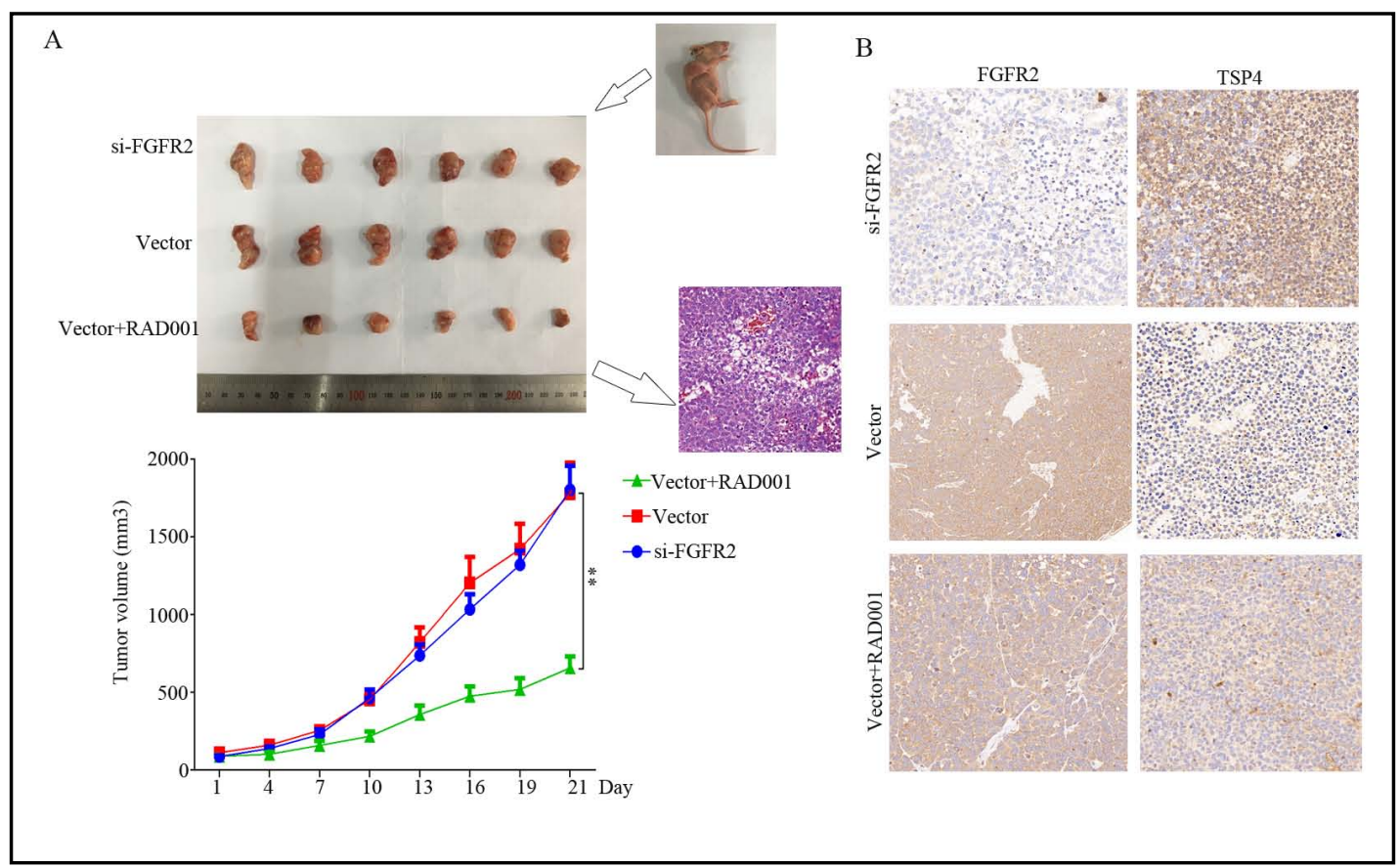

Fig. 5. RAD001 inhibits tumor growth and elevates TSP4 expression in xenograft model. Mice were randomly divided into three groups (SGC7901 cells with FGFR2-knockdown group, vector group, and vector + RAD001group). RAD001 was administered by oral gavage ( $2 \mathrm{mg} / \mathrm{kg} /$ day). (A) Tumor tissues at the end of treatment and tumor volumes over 21 days. (B) Representative IHC staining of FGFR2 and TSP4 from tumor samples in each group (magnification, $\times 200)$. Data are presented as mean \pm SEM $\left({ }^{* *} \mathrm{P}<0.01\right)$.

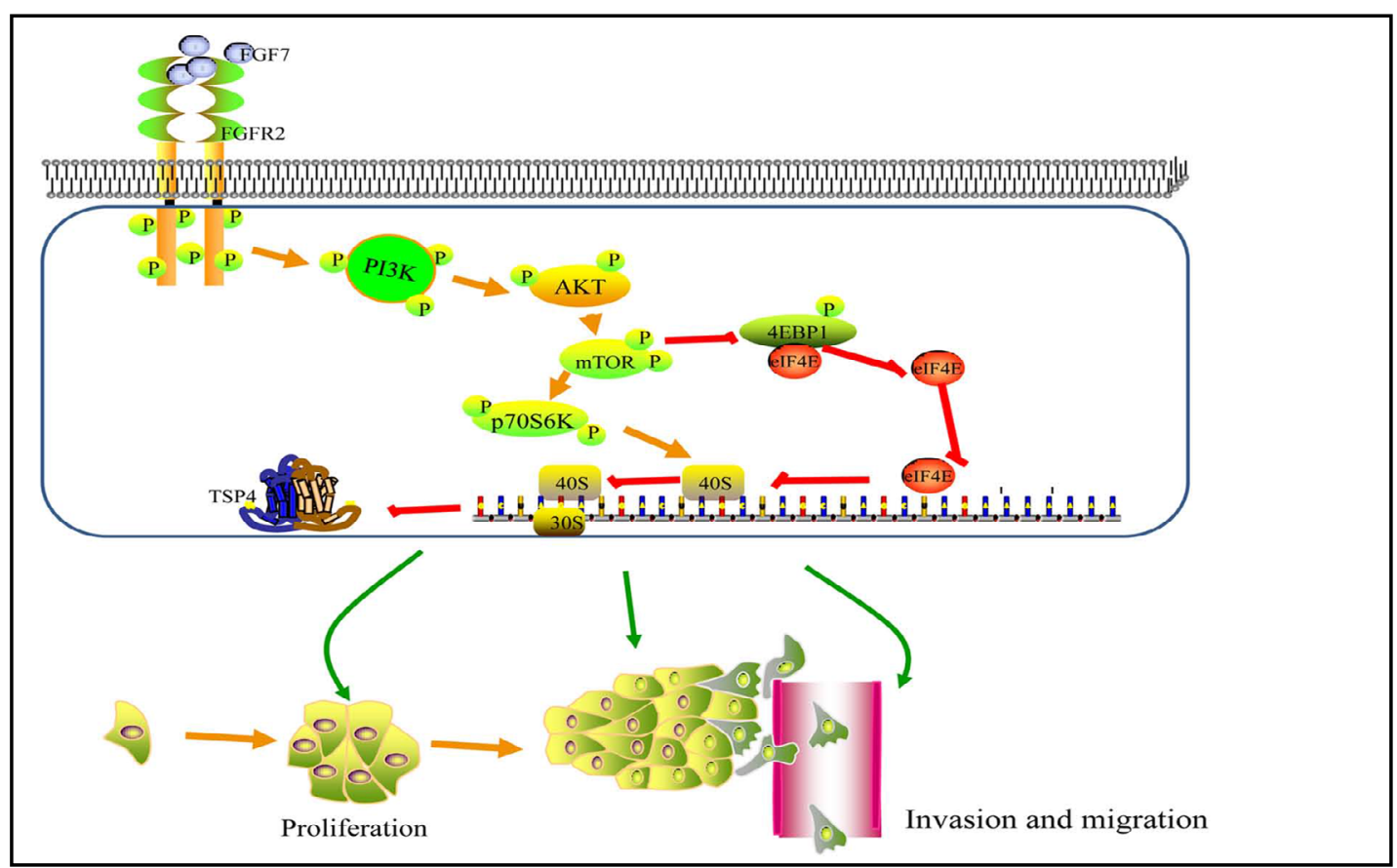

Fig. 6. The FGFR2-TSP4 axis promotes GC progression. The FGFR2 signal activates the PI3K-AKT- mTOR pathway resulting in the suppression of 4EBP1 phosphorylation and decreased the release of eIF-4E, which may inhibit the mRNA translation of TSP4. The FGFR2-TSP4 axis plays an important role in GC cells proliferation, invasion and migration.

\section{KARGER}




\section{Cellular Physiology Cell Physiol Biochem 2018;50:1332-1345 \begin{tabular}{ll|l} 
and Biochemistry Published online: 25 October 2018 & $\begin{array}{l}\text { (c) } 2018 \text { The Author(s). Published by S. Karger AG, Basel } \\
\text { www.karger.com/cpb }\end{array}$ \\
\hline
\end{tabular} \\ Huang et al.: FGFR2-TSP4 Axis in Gastric Cancer}

\section{Discussion}

Expression levels of FGFR2 and TSPs assessed independently have been reported in several studies as prognostic factors for patients with GC [17-20]. As a follow-on from our previous study, which demonstrated that FGFR2 promotes GC cells invasion and migration by targeting TSPs in vitro [16], we undertook an evaluation of the potential clinical significance and mechanism of the relationship between FGFR2 and TSP4 in GC.

FGFR2 has been investigated as a potential therapeutic target in several solid tumors including lung cancer, colon cancer, and GC $[21,22]$. Previous studies have reported that the prevalence of FGFR2 amplification in GC was $4 \%$ to $7 \%$ and correlated with aggressive tumor behavior [23, 24]. In our study, FGFR2 was shown to be markedly overexpressed in GC tissues and correlated with a high risk of lymph node metastasis and late clinical stage. Our findings suggested that FGFR2 overexpression was associated with advanced disease and poor prognosis.

Our data showed that low TSP4 expression was associated with shorter OS and an advanced stage of GC, which is in contrast to the study by Forster et al. in which TSP4 was reported to be a powerful marker for diffuse-type GC [19]. Some reports have shown TSP4 protein expression may facilitate invasion of tumor cells in breast cancer and hepatocellular carcinoma $[12,25]$. In contrast, another study reported that TSP4 may act as a tumor suppressor gene in colorectal cancer [26]. There are several possible reasons for the discrepancies between these findings: First, tumor progression is a dynamic, precisely regulated, multistep process, and TSP4 is an inducible marker that can be upregulatedor downregulated over time [27]. Second, the determination of TSP4 expression is generally performed via IHC using different antibodies for different malignancies. Third, the threshold for TSP4 overexpression differed among the previous studies, and the optimal threshold for TSP4 overexpression remains undefined and warrants further investigation. Interestingly, the findings of correlation analysis indicate that FGFR2 might be negatively associated with TSP4. Indeed, in vitro and in vivo experiments suggested that FGFR2 activation could downregulate TSP4 expression, which played an important role in the proliferation, invasion and migration of GC cells.

Associations between FGFR and TSP members have been previously reported by our group and others $[15,16,28,29]$. The production of TSPs is associated with FGFs and determines tumor invasion and metastasis. Our results show that the expression levels of FGFR2 and TSP4 are not independent prognostic factors in GC that indicate a connection between FGFR2 and TSP4. Furthermore, we have revealed the mechanism of the relationship between FGFR2 and TSP4. The activation of FGFRs modulates multiple signal transduction pathways. The best understood of these are the PI3K-AKT and the RAS-MAP kinase pathways, which include ERK1/2, p38 and JNK kinases [30]. Using small molecule inhibitors, we found that the PI3K-AKT-mTOR pathway was involved in the FGFR2-TSP4 axis. The administration of FGF7 significantly and rapidly activated mTOR. The expression of TSP4 was elevated when mTOR was knocked down in GC cells or mice administrated with mTOR inhibitor. Evidence suggested that the activation of the PI3K-AKT-mTOR pathway played a major role in several cellular functions that are critical to tumorigenesis such as cellular proliferation, survival, and mobility [31]. The use of an mTOR inhibitor in our xenograft models demonstrated its antitumor effects on GC. However, knockdown of FGFR2 did not affect tumor growth in mice. We suspect that the environment in vivo may enable the growth of GC. Based on these observations, novel drugs with different mechanisms of action in the inhibition of mTOR may be more active in GC, particularly in patients with FGFR2-TSP4 axis alternations.

Phosphorylated 4EBP1 reduced the affinity with eukaryotic initiation factor 4E (eIF$4 \mathrm{E})$, thereby blocking the suppression of 4EBP1 on eIF-4E blocking and translation. Dissociative eIF-4E band with eIF-4G/eIF-4A/eIF-4B formed eIF-4F complex and further coupled to the cap structure of the mRNA 5'-terminal. It promoted mRNA translation and protein synthesis, thus accelerating cell growth and proliferation [32]. Recent reports have suggested that 4EBP1 phosphorylation correlates directly with the malignancy and severity 
of various tumors [33-35]. Interestingly, we found the activation of FGFR2 significantly suppressed 4EBP1 phosphorylation, thus decreasing the release of eIF-4E. This event may inhibit the mRNA translation of TSP4, which could explain the downregulation of TSP4 after FGFR2 activation (Fig. 6). Although mTOR seems to be the chief phosphorylation pathway of 4EBP1, other unidentified kinases and mechanisms are also involved, given that multiple phosphorylation sites in 4EBP1 are partially insensitive to rapamycin [33, 36-38]. However, the exact molecular mechanism in the FGFR2-TSP4 axis merits further investigation.

Blockade of FGFR2 has resulted in durable tumor regression and prolonged disease stabilization in xenograft models, suggesting the promise of FGFR2-targeted therapy. Indeed, new small molecule inhibitors of FGFR are currently being evaluated in clinical trials. Recent data have shown that alterations in FGFR are associated with response to high potent FGFR inhibitors. However, the multitargeted tyrosine kinase inhibitors (TKIs) with FGFR inhibitory activity have not been shown to be superior to standard chemotherapy in most clinical trials, suggesting that both the drug and target are important [39]. FGFR2-related signaling plays an important role in GC progression through diverse mechnisms, so FGFR2 may regulates different pathways in different GC cells. The identification of biomarkers of FGFR2-based therapy can help in selecting the right patient populations for personalized therapy. The combination of FGFR2 inhibitors and other agents such as mTOR inhibitors or TSPs-related agents may deliver better results for GC patients. Continued basic research is needed to gain further insights into the role that the FGFR2 signal pathway plays in the progression of tumors.

Our study also had certain limitations. First, the number of patients enrolled was relatively small, and the sample lacked stage IV patients. Thus, the sample may not adequately represent the entire patient group. Second, the therapies received by these patients were not standardized, which might have affected the survival outcomes. Further investigations of larger sample populations should balance out most of the relevant clinical factors and are needed to further verify our findings.

\section{Conclusion}

In conclusion, FGFR2 signaling was found to promote the progression of human GC through the down-regulation of TSP4 via the PI3K-AKT-mTOR pathway. To our knowledge, this is the first study to characterize the relationship of FGFR2 and TSP4 in GC, which is significantly associated with a poor prognosis, and the promotion of GC cells proliferation, invasion, and migration. Our findings provide the foundation for further research on the FGFR2/TSP4 as a potential target for GC.

\section{Acknowledgements}

This work was supported by the National Natural Science Foundation of China (Grant Number: 81372664) and the Ministry of Science and Technology of China (Grant Number: 2016YFC0904701).

\section{Disclosure Statement}

The authors declare that they have no conflicts of interests. 


\section{Cellular Physiology Cell Physiol Biochem 2018;50:1332-1345

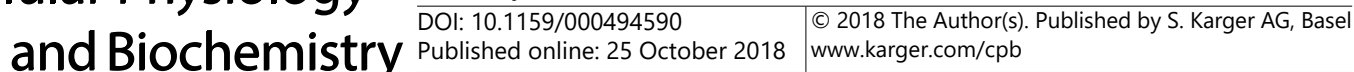

Huang et al.: FGFR2-TSP4 Axis in Gastric Cancer

\section{References}

1 Torre LA, Bray F, Siegel RL, Ferlay J, Lortet-Tieulent J, Jemal A: Global cancer statistics, 2012. CA Cancer J Clin 2015;65:87-108.

-2 Shah MA: Update on metastatic gastric and esophageal cancers. J Clin Oncol 2015;33:1760-1769.

- 3 Turner N, Grose R: Fibroblast growth factor signalling: from development to cancer. Nat Rev Cancer 2010;10:116-129.

-4 Ornitz DM, Itoh N: The Fibroblast Growth Factor signaling pathway. Wiley Interdiscip Rev Dev Biol 2015;4:215-266.

-5 Babina IS, Turner NC: Advances and challenges in targeting FGFR signalling in cancer. Nat Rev Cancer 2017;17:318-332.

-6 Lieu C, Heymach J, Overman M, Tran H, Kopetz S: Beyond VEGF: inhibition of the fibroblast growth factor pathway and antiangiogenesis. Clin Cancer Res 2011;17:6130-6139.

7 Beenken A, Mohammadi M: The FGF family: biology, pathophysiology and therapy. Nat Rev Drug Discov 2009;8:235-253.

8 Toyokawa T, Yashiro M, Hirakawa K: Co-expression of keratinocyte growth factor and K-sam is an independent prognostic factor in gastric carcinoma. Oncol Rep 2009;21:875-880.

-9 Bornstein P: Thrombospondins function as regulators of angiogenesis. J Cell Commun Signal 2009;3:189200.

10 Muppala S, Xiao R, Krukovets I, Verbovetsky D, Yendamuri R, Habib N, Raman P, Plow E, Stenina-Adognravi O: Thrombospondin-4 mediates TGF-beta-induced angiogenesis. Oncogene 2017;36:5189-5198.

-11 Guo Y, Zhang Z, Wu HE, Luo ZD, Hogan QH, Pan B: Increased thrombospondin-4 after nerve injury mediates disruption of intracellular calcium signaling in primary sensory neurons. Neuropharmacology 2017;117:292-304.

12 McCart Reed AE, Song S, Kutasovic JR, Reid LE, Valle JM, Vargas AC, Smart CE, Simpson PT: Thrombospondin-4 expression is activated during the stromal response to invasive breast cancer. Virchows Arch 2013;463:535-545.

$>13$ Liu J, Cheng G, Yang H, Deng X, Qin C, Hua L, Yin C: Reciprocal regulation of long noncoding RNAs THBS4003 and THBS4 control migration and invasion in prostate cancer cell lines. Mol Med Rep 2016;14:1451-1458.

14 Lin X, Hu D, Chen G, Shi Y, Zhang H, Wang X, Guo X, Lu L, Black D, Zheng XW, Luo X: Associations of THBS2 and THBS4 polymorphisms to gastric cancer in a Southeast Chinese population. Cancer Genet 2016;209:215-222.

15 Mattila MM, Tarkkonen KM, Seppanen JA, Ruohola JK, Valve EM, Harkonen PL: Androgen and fibroblast growth factor 8 (FGF8) downregulation of thrombospondin 1 (TSP1) in mouse breast cancer cells. Mol Cell Endocrinol 2006;253:36-43.

16 Huang T, Wang L, Liu D, Li P, Xiong H, Zhuang L, Sun L, Yuan X, Qiu H: FGF7/FGFR2 signal promotes invasion and migration in human gastric cancer through upregulation of thrombospondin-1. Int J Oncol 2017;50:1501-1512.

17 Zhuo C, Li X, Zhuang H, Tian S, Cui H, Jiang R, Liu C, Tao R, Lin X: Elevated THBS2, COL1A2, and SPP1 Expression Levels as Predictors of Gastric Cancer Prognosis. Cell Physiol Biochem 2016;40:1316-1324.

-18 Kashihara H, Shimada M, Yoshikawa K, Higashijima J, Tokunaga T, Nishi M, Takasu C, Ishikawa D: Correlation Between Thrombospondin-1 Expression in Non-cancer Tissue and Gastric Carcinogenesis. Anticancer Res 2017;37:3547-3552.

19 Forster S, Gretschel S, Jons T, Yashiro M, Kemmner W: THBS4, a novel stromal molecule of diffusetype gastric adenocarcinomas, identified by transcriptome-wide expression profiling. Mod Pathol 2011;24:1390-1403.

20 Ahn S, Lee J, Hong M, Kim ST, Park SH, Choi MG, Lee JH, Sohn TS, Bae JM, Kim S, Jung SH, Kang WK, Kim KM: FGFR2 in gastric cancer: protein overexpression predicts gene amplification and high H-index predicts poor survival. Mod Pathol 2016;29:1095-1103.

21 Jang JH, Shin KH, Park JG: Mutations in fibroblast growth factor receptor 2 and fibroblast growth factor receptor 3 genes associated with human gastric and colorectal cancers. Cancer Res 2001;61:3541-3543.

22 Davies H, Hunter C, Smith R, Stephens P, Greenman C, Bignell G, Teague J, Butler A, Edkins S, Stevens C, Parker A, O’Meara S, Avis T, Barthorpe S, Brackenbury L, Buck G, Clements J, Cole J et al. : Somatic mutations of the protein kinase gene family in human lung cancer. Cancer Res 2005;65:7591-7595. 


\section{Cellular Physiology Cell Physiol Biochem 2018;50:1332-1345 \begin{tabular}{ll|l} 
DOl: 10.1159/000494590 & $\begin{array}{l}\text { O } 2018 \text { The Author(s). Published by S. Karger AG, Basel } \\
\text { www.karger.com/cpb }\end{array}$ \\
\hline
\end{tabular}}

Huang et al.: FGFR2-TSP4 Axis in Gastric Cancer

-23 Su X, Zhan P, Gavine PR, Morgan S, Womack C, Ni X, Shen D, Bang YJ, Im SA, Ho Kim W, Jung EJ, Grabsch HI, Kilgour E: FGFR2 amplification has prognostic significance in gastric cancer: results from a large international multicentre study. Br J Cancer 2014;110:967-975.

-24 Jung EJ, Jung EJ, Min SY, Kim MA, Kim WH: Fibroblast growth factor receptor 2 gene amplification status and its clinicopathologic significance in gastric carcinoma. Hum Pathol 2012;43:1559-1566.

-25 Su F, Zhao J, Qin S, Wang R, Li Y, Wang Q, Tan Y, Jin H, Zhu F, Ou Y, Cheng Z, Su W, Zhao F, Yang Y, Zhou Z, Zheng J, Li Y, Li Z, Wu Q: Over-expression of Thrombospondin 4 correlates with loss of miR-142 and contributes to migration and vascular invasion of advanced hepatocellular carcinoma. Oncotarget 2017;8:23277-23288.

-26 Greco SA, Chia J, Inglis KJ, Cozzi SJ, Ramsnes I, Buttenshaw RL, Spring KJ, Boyle GM, Worthley DL, Leggett BA, Whitehall VL: Thrombospondin-4 is a putative tumour-suppressor gene in colorectal cancer that exhibits age-related methylation. BMC Cancer 2010;10:494.

27 Huang T, Sun L, Yuan X, Qiu H: Thrombospondin-1 is a multifaceted player in tumor progression. Oncotarget 2017;8:84546-84558.

28 Horiguchi H, Jin L, Ruebel KH, Scheithauer BW, Lloyd RV: Regulation of VEGF-A, VEGFR-I, thrombospondin-1, -2 , and -3 expression in a human pituitary cell line (HP75) by TGFbeta1, bFGF, and EGF. Endocrine 2004;24:141-146.

29 Borsotti P, Ghilardi C, Ostano P, Silini A, Dossi R, Pinessi D, Foglieni C, Scatolini M, Lacal PM, Ferrari R, Moscatelli D, Sangalli F, D’Atri S, Giavazzi R, Bani MR, Chiorino G, Taraboletti G: Thrombospondin-1 is part of a Slug-independent motility and metastatic program in cutaneous melanoma, in association with VEGFR-1 and FGF-2. Pigment Cell Melanoma Res 2015;28:73-81.

-30 Dailey L, Ambrosetti D, Mansukhani A, Basilico C: Mechanisms underlying differential responses to FGF signaling. Cytokine Growth Factor Rev 2005;16:233-247.

-31 Marone R, Cmiljanovic V, Giese B, Wymann MP: Targeting phosphoinositide 3-kinase: moving towards therapy. Biochim Biophys Acta 2008;1784:159-185.

-32 Darb-Esfahani S, Faggad A, Noske A, Weichert W, Buckendahl AC, Muller B, Budczies J, Roske A, Dietel M, Denkert C: Phospho-mTOR and phospho-4EBP1 in endometrial adenocarcinoma: association with stage and grade in vivo and link with response to rapamycin treatment in vitro. J Cancer Res Clin Oncol 2009;135:933-941.

-33 Armengol G, Rojo F, Castellvi J, Iglesias C, Cuatrecasas M, Pons B, Baselga J, Ramon y Cajal S: 4E-binding protein 1: a key molecular "funnel factor" in human cancer with clinical implications. Cancer Res 2007;67:7551-7555.

34 Nishikawa M, Miyake H, Harada K, Fujisawa M: Expression level of phosphorylated-4E-binding protein 1 in radical nephrectomy specimens as a prognostic predictor in patients with metastatic renal cell carcinoma treated with mammalian target of rapamycin inhibitors. Med Oncol 2014;31:792.

-35 Qu Y, Zhao R, Wang H, Chang K, Yang X, Zhou X, Dai B, Zhu Y, Shi G, Zhang H, Ye D: Phosphorylated 4EBP1 is associated with tumor progression and poor prognosis in Xp11.2 translocation renal cell carcinoma. Sci Rep 2016;6:23594.

-36 Wang X, Beugnet A, Murakami M, Yamanaka S, Proud CG: Distinct signaling events downstream of mTOR cooperate to mediate the effects of amino acids and insulin on initiation factor 4E-binding proteins. Mol Cell Biol 2005;25:2558-2572.

-37 She QB, Halilovic E, Ye Q, Zhen W, Shirasawa S, Sasazuki T, Solit DB, Rosen N: 4E-BP1 is a key effector of the oncogenic activation of the AKT and ERK signaling pathways that integrates their function in tumors. Cancer Cell 2010;18:39-51.

-38 Gingras AC, Raught B, Gygi SP, Niedzwiecka A, Miron M, Burley SK, Polakiewicz RD, Wyslouch-Cieszynska A, Aebersold R, Sonenberg N: Hierarchical phosphorylation of the translation inhibitor 4E-BP1. Genes Dev 2001;15:2852-2864.

-39 Morales-Barrera R, Suarez C, de Castro AM, Racca F, Valverde C, Maldonado X, Bastaros JM, Morote J, Carles J: Targeting fibroblast growth factor receptors and immune checkpoint inhibitors for the treatment of advanced bladder cancer: New direction and New Hope. Cancer Treat Rev 2016;50:208-216. 